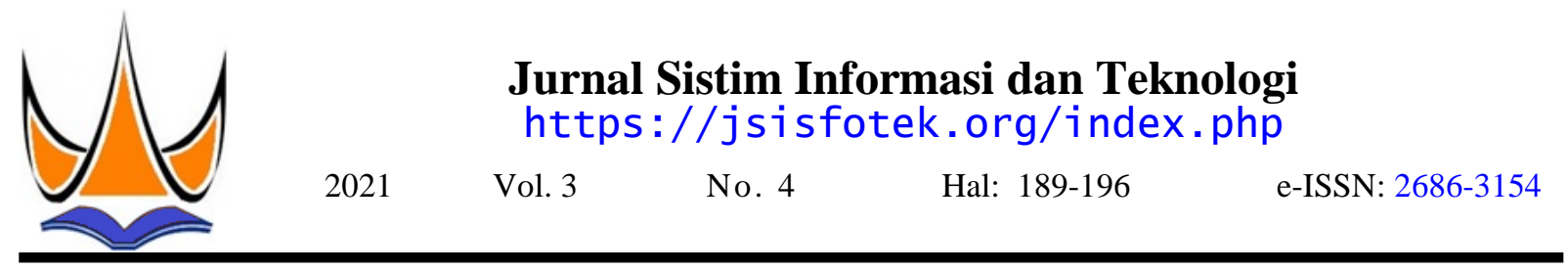

\title{
Perangkingan Potensi Guru dalam Penentuan Calon Kepala Sekolah Menggunakan Metode TOPSIS
}

\author{
Bendra Wardana ${ }^{1 凶}$, Sumijan $^{2}$ \\ ${ }^{1,2}$ Universitas Putra Indonesia YPTK Padang \\ bendwardana@gmai1.com
}

\begin{abstract}
Efforts to increase the value of the quality of education for students as the next generation of the nation require teachers who have competence in providing education to students. The competence of a teacher can be assessed when a teacher has carried out his duties in accordance with the standard provisions he has. The ranking of potential teachers is used to motivate teachers to be active in carrying out each activity and is expected to have a positive effect on their work to face challenges in this era of globalization. The data that is processed for the ranking of teacher potential is the assessment data of elementary school teachers sourced from the korwildik of the Batang kapas sub-district. This ranking is based on several criteria and weights are determined. Furthermore, this ranking is processed using a system created by the researcher. This ranking uses a method called TOPSIS to assist researchers in ranking. The TOPSIS method is a multi-criteria decision support method with the principle that the chosen alternative must have the closest distance from the positive and negative ideal solutions. The results of ranking with the TOPSIS method are able to support the ranking decisions of potential teachers using predetermined criteria. So that the highest value is found in the 5th alternative with a value of 0.7321 and the lowest value is found in the 1 st alternative with a value of 0.2218 . The ranking of potential teachers has proven to be able to help the South Coast District Education and Culture Office, especially the korwildik of the Batang kapas sub-district in determining prospective school principals.
\end{abstract}

Keywords: Ranking, Potential, Teacher, TOPSIS, Principal.

Abstrak

Upaya dalam meningkatkan nilai mutu suatu pendidikan untuk siswa sebagai generasi penerus bangsa dibutuhkan guru yang memiliki kompetensi dalam memberikan pendidikan terhadap siswa. Kompetensi seorang guru dapat dinilai ketika seorang guru telah melakukan tugasya sesuai dengan standar ketentuan yang dimiliki. Perangkingan potensi guru difungsikan untuk memotivasi guru agar giat dalam melakukan setiap aktivitas dan diharapkan akan berpengaruh positif terhadap kerjanya untuk menghadapi tantangan di era globalisasi ini. Data yang diolah untuk perangkingan potensi guru merupakan data penilaian guru sekolah dasar yang bersumber dari korwildik kecamatan batang kapas. Perangkingan ini didasarkan terhadap beberapa kriteria dan bobot yang ditentukan. Selanjutnya perangkingan ini diolah menggunakan sebuah sistem yang dibuat oleh peneliti. Perangkingan ini menggunakan sebuah metode yang dinamakan TOPSIS untuk membantu peneliti dalam melakukan perangkingan. Metode TOPSIS adalah salah satu metode pendukung keputusan multikriteria dengan prinsip alternatif yang dipilih harus memiliki jarak yang paling dekat dari solusi ideal positif dan negative. Hasil dari perangkingkan dengan metode TOPSIS adalah dapat mendukung keputusan perangkingan potensi guru menggunakan kriteria-kriteria yang telah ditentukan. Sehingga didapat nilai tertinggi ada pada alternatif ke 5 dengan nilai 0.7321 dan nilai yang terendah terdapat pada alternatif ke 1 dengan nilai 0.2218 . Perangkingan potensi guru terbukti dapat membantu Dinas pendidikan dan kebudayaan kabupaten pesisir selatan khususnya korwildikcam kecamatan batang kapas dalam penentuan calon kepala sekolah.

Kata kunci: Perangkingan, Potensi, Guru, TOPSIS, Kepala Sekolah.

(C) 2021 JSisfotek

\section{Pendahuluan}

Upaya dalam meningkatkan nilai mutu suatu pendidikan untuk siswa sebagai generasi penerus bangsa dibutuhkan guru yang memiliki kompetensi dalam memberikan pendidikan terhadap siswa. Dalam era saat ini pemanfaatan ilmu pengetahuan dan teknologi berkembang dengan sangat cepat dan menghasilkan inovasi baru yang harus diimbangi dengan kemampuan beradaptasi dengan teknologi tesebut. Dalam perangkingan potensi guru kita bisa melakukan penelitian terhadap aspek kinerja ataupun kompetensinya. Guru yang berkompentensi merupakan guru yang memiliki keahlian dalam proses belajar mengajar, manajemen, dan kemampuanya dalam melaksanakan tugas, serta memiliki wawasan 
kependidikan sehingga secara nyata dapat pengambilan keputusan yang tepat dalam penilaian meningkatkan mutu pendidikan berdasarkan proses dan kinerja guru [5].

hasil pembelajaran. Dalam upaya meningkatan nilai mutu pendidikan di Kabupaten Pesisir Selatan, pihak dinas pendidikan melakukan sebuah proses penilaian terhadap guru dengan cara menilai potensi-potensi yang dimiliki dengan tujuan untuk memberikan suatu rekomendasi dalam menduduki jabatan kepala sekolah. Permasalahan yang ada saat ini belum adanya sistem yang membantu dalam melakukan penilaian atau perangkingan potensi guru tersebut. Perangkingan potensi guru dimaksudkan untuk memotivasi guru agar giat dalam melakukan setiap aktivitas dan yang diharapkan akan berpengaruh positif terhadap kerjanya untuk menghadapi tantangan di era globalisasi ini.

Penelitian lainya, SMK Negeri 1 Labu melakukan pemilihan guru berprestasi dengan cara memiliki tahapan-tahapan tertentu, akan tetapi belum optimal didalam pelaksanaanya. Langkah terbaik dalam mengoptimalkanya dengan cara membangun sistem pendukung keputusan untuk membantu dalam pengambilan keputusan untuk pemilihan guru berprestasi. Kriteria yang digunakan dalam penelitian ini sebanyak 7 kriteria dan memiliki bobot kepentingan masing-masing. Dengan menggunakan metode TOPSIS ini dapat membantu pihak sekolah dalam memilih guru berprestasi [6].

Dalam melakukan perangkingan potensi guru kita bisa Dalam penelitian yang lain dengan menggunakan menyelenggarakan secara profesional dan obyektif metode yang sama, penilaian kinerja dosen dapat yang berarti perangkingan dilakukan secara bersaing dilakukan oleh siapa saja. Setiap penilaian yang atas kemampuan dan keterampilan serta potensi dilakukan oleh atasan ataupun mahasiswa masih kerjanya, bukan berdasarkan pemerataan kesempatan memiliki kelemahan dalam melakukan penilaian untuk mengikuti perangkingan potensi guru tersebut tersebut. Dalam melakukan penilaian, metode TOPSIS agar proses perangkingan dapat lebih terstruktur, tepat, adalah salah satu metode yang bisa menyelesaikan dan mudah dilakukan. Selain itu, proses pemantauan permasalahan tersebut. Mengingat TOPSIS, memiliki potensi guru akan lebih mudah untuk dilakukan oleh ketentuan optimal alternatif diputuskan dengan pihak sekolah serta ditindak lanjuti dengan proses menghitung jarak masing-masing alternatif [7]. Dalam evaluasi ataupun perencanaan-perancanaan lainya yang penelitian, dengan menggunakan metode ini dapat berhubungan dengan potensi guru yang difungsikan memberikan rekomendasi dan mengevaluasi dosen, sebagai promosi untuk rekomendasi menjadi calon dimana nilai tertinggi dijadikan prioritas pertama kepala sekolah [1].

sebagai dosen yang memiliki kinerja tinggi [8].

Dalam memudahkan proses perangkingan maka Metode TOPSIS memiliki prinsip, dengan diperlukan adanya sistem terkomputerisasi dalam menggunakan prinsip bahwa alternatif yang dipilih membantu melakukan proses perangkingan memiliki jarak terpanjang dari solusi ideal negative [9]. berdasarkan kriteria-kriteria yang sudah ada, dan Kriteria yang digunakan dalam penelitian ini, terdapat 5 merangking guru akan yang menduduki jabatan calon kriteria yang memiliki nilai bobot yang berbeda. Hasil kepala sekolah. Didalam sebuah teknologi informasi, yang didapatkan bahwa metode TOPSIS dapat sistem pendukung keputusan merupakan cabang ilmu memberikan bantuan dalam proses penentuan guru yang terletak antara sistem informasi dan sistem cerdas. berprestasi yang bersifat sistem rekomendasi [10]. Sistem pendukung keputusan dirancang untuk semua Penelitian selanjutnya tentang evaluasi alokasi sumber tahap pengambilan keputusan, dimulai dari identifikasi daya pendidikan di Beijing menghasilkan bahwa masalah, memilih data yang sesuai, mendefenisikan metode TOPSIS telah dikembangkan untuk evaluasi pendekatan yang digunakan dalam proses pengambilan alokasi sumber daya pendidikan pelatihan. Evaluasi keputusan [2]. Metode yang digunakan adalah metode alokasi sumber daya total pendidikan diklat perguruan TOPSIS, TOPSIS menyarankan yang optimal alternatif tinggi kejuruan di Beijing dari 2016 hingga 2019 dapat dari serangkaian alternatif harus menyajikan yang tercapai [11]. terpendek jarak geometris dari solusi ideal positif [3]. Metode ini menggunakan nilai kriteria yang sesuai dengan bobot, membandingkan sifat alternatif dari ideal positif dan negative, dan persamaan matriks matematika [4].

Dalam penelitian lain, metode TOPSIS digunakan dalam sistem pendukung keputusan untuk menentukan guru berprestasi pada SMP. Kriteria yang digunakan terdapat 5 komponen kriteria didalamnya dan memiliki nilai bobot yang berbeda pada masing-masingnya. Ada banyak peneliti sebelumnya yang telah melakukan Hasil yang didapatkan adalah dapat memberikan hasil penelitian penilaian kinerja guru menggunakan metode perangkingan berdasarkan nilai preferensi [12]. TOPSIS. Metode ini bisa membantu proses Penelitian lainya dengan menggunakan metode yang pengambilan keputusan yang lebih optimal untuk sama mendapatkan bahwa dengan menggunakan menyelesaikan permasalahan. Dalam permasalahan ini metode TOPSIS dapat menghasilkan nilai kelayakan data yang diambil adalah data guru dan bobot kriteria penerima Kartu Keluarga Sejahtera (KKS) secara sebagai acuan dalam melakukan penilaian. Berdasarkan objektif berdasarkan urutan nilai tertinggi [13].

penelitian yang dilakukan bahwa Metode TOPSIS dapat membantu peneliti sebagai alat untuk

Penelitian terdahulu yang telah dilakukan dengan menggunakan metode TOPSIS adalah dalam 
mengevaluasi kinerja dosen oleh mahasiswa. Dimana Metode tersebut bersifat objektif, artinya objektivitas proses evaluasi ini dilakukan secara berkala dalam tersebut mampu menghasilkan penelitian yang dapat setiap akhir semester dan dilakukan secara kualitatif. dijadikan sebagai acuan oleh peneliti lainnya. Metode Data yang didapatkan dalam penelitian ini tersebut memiliki sifat yang kritis, serta secara analisis menggunakan teknik wawancara langsung dengan mampu menunjukan proses yang tepat dan benar dalam pihak terkait. Kriteria yang digunakan berjumlah 10 mendefenisikan masalah dengan suatu metode. Metode kriteria dengan mengajukan pertanyaan, dan alternatif- yang digunakan juga memiliki sifat yang logis, berarti alternatif yang digunakan adalah para dosen yang mampu memberikan argumen yang baik. Pada bagian mengampu mata kuliah. Hasil yang didapatkan adalah ini penulis melaksanakan studi literatur termasuk dibangunya sistem pendukung keputusan menggunakan dengan membaca dan mengumpulkan berbagai bahan metode TOPSIS dapat membantu dalam mengevaluasi dari buku-buku, jurnal-jurnal komputer yang kinerja dosen [14].

Penelitian yang dilakukan sebelumnya. Metode TOPSIS ini diterapkan untuk membantu SMK Perintis 1 Depok untuk membantu dalam melakukan penilaian guru terbaik. Dalam penelitian ini, sistem pendukung keputusan pemilihan guru dilakukan dengan tahapan, observasi, wawancara dan studi pustaka. Kriteria yang digunakan dalam pemilihan guru terbaik terdapat 15 kriteria dan alternatif yang digunakan adalah 26 guru Kerangka kerja merupakan tahapan yang harus yang akan menjadi kandidat untuk dipromosikan dilakukan dalam menyelesaikan permasalahan yang sebagai guru terbaik. Hasil yang didapatkan bahwa akan dibahas. Kerangka kerja bertujuan untuk membuat metode TOPSIS memiliki tingkat akurasi yang tinggi serta menjelaskan tahapan-tahapan yang akan dibanding dengan metode SAW [15]. Penelitian lainya dilakukan dalam penelitian. Setiap tahapan akan Pendekatan manipulasi bobot strategis evolusioner dilakukan sesuai dengan perencanaan. Setiap tahapan untuk pengambilan keputusan multi-atribut, akan berpengaruh dengan tahapan selanjutnya. Adapun menghasilkan bahwa metode TOPSIS telah kerangka kerja pada penelitian yang dilakukan dapat mempertimbangkan strategi manipulasi bobot strategis dilihat pada Gambar 1.

didalam pengambilan keputusan. rentang peringkat memungkinkan dalam memvisualisasikan variasi peringkat alternatif atas bobot yang digunakan [16].

Berdasarkan penelitian terdahulu, untuk menilai kinerja guru dengan metode TOPSIS terdapat beberapa kriteria kompetensi yang harus terpenuhi dan berjumlah 4 kriteria yang memiliki sub-sub kiteria didalamya. Tingkat kepentingan kriteria berdasarkan nilai bobot, dan skala penilaian yang dilakukan menggunakan Skala Linkerd. Hasil implementasi yang dilakukan dengan metode TOPSIS mendapatkan keputusan penilaian status berdasarkan, Kurang baik, baik dan sangat baik [17].

\section{Metodologi Penelitian}

Metode penelitian merupakan rancangan dari kegiatan penelitian yang dilakukan dalam mencari, merumuskan serta menganalisa hingga dapat menyusun sesuatu dengan langkah-langkah yang akan digunakan dan waktu yang dapat digunakan sebagai acuan dalam memperoleh dalam analisa data. Metode penelitian diperlukan guna untuk membantu penulisan dapat terarah sesuai dengan masalah yang diteliti. Penelitian adalah cara yang sistematis untuk menjawab suatu Adapun uraian tahapan yang dilakukan pada penelitian masalah yang akan di teliti dan dari kata sistematis ini yaitu:

sendiri ada kaitannya dengan metode ilmiah yang berarti ada keterkaitan prosedur yang ditandai dengan adanya ketuntasan dan keteraturan.

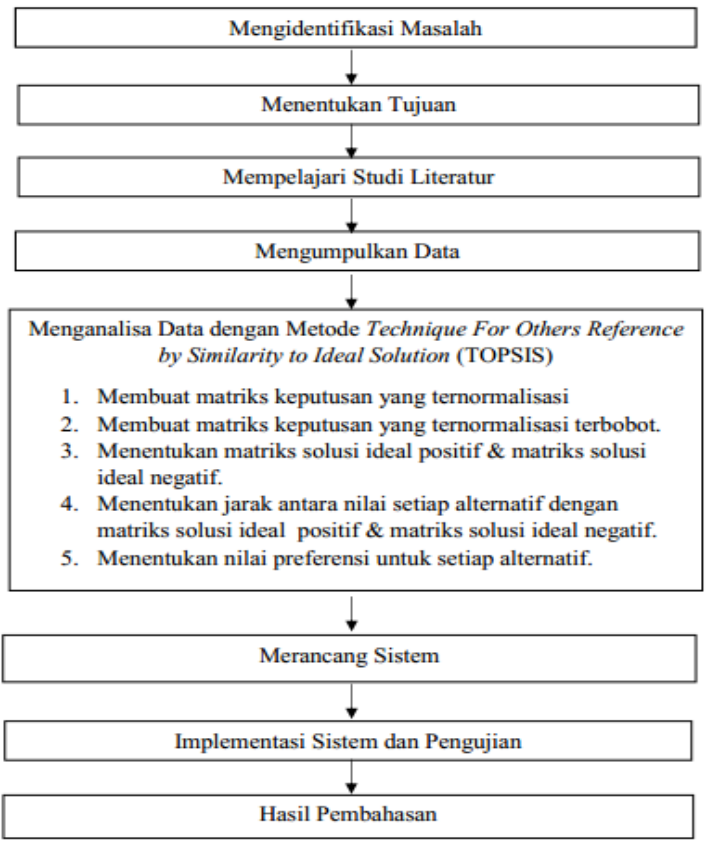

Gambar 1. Kerangka Kerja Penelitian

\subsection{Mengidentifikasi masalah}

Tahapan identifikasi masalah merupakan langkah pertama yang akan dilakukan dalam penelitian ini. Tahap ini sangat penting karena peneliti melakukan 
perumusan dari masalah yang ditemukan pada dalam pendidikan dan kebudayaan untuk melakukan objek penelitian dan memberikan batasan dari pengembangan sistem. permasalahan yang di temukan agar lebih terarah.

\subsection{Menentukan tujuan penelitian}

\section{Hasil dan Pembahasan}

Pada tahap ini diperlihatkan tujuan yang ingin dicapai oleh peneliti melalui proses penelitian. Tujuan penelitian harus jelas dan tegas. Tujuan penelitian adalah suatu target yang akan dicapai untuk mengatasi masalah-masalah yang ada.

\subsection{Mempelajari literatur}

Setelah dilakukan identifikasi masalah, kemudian menganalisa data dan menetukan tujuan yang akan dicapai, langkah selanjutnya adalah mempelajari literatur yang berhubungan dengan judul. Sumber literatur didapatkan dari buku, jurnal, artikel, yang membahas tentang Metode TOPSIS, Sistem pendukung keputusan dan bahan bacaan lain yang mendukung penelitian.

2.4 Mengumpulkan data.

3.1 Analisa dan perancangan

Analisa sistem yang akan dianalisa, harus melakukan beberapa langkah untuk memahami semua prosedur yang ada didalam sistem. Langkah-langkah didalam tahap analisa sistem hampir sama dengan langkahlangkah yang dilakukan dalam mendefenisikan proyekproyek sistem yang akan dikembangkan ditahap perencanaan sistem, perbedaannya terletak pada ruang lingkup tugasnya. Guna memudahkan dalam analisa dan perancangan sistem maka dibuat bagan alir analisa dan perancangan seperti pada Gambar 2.

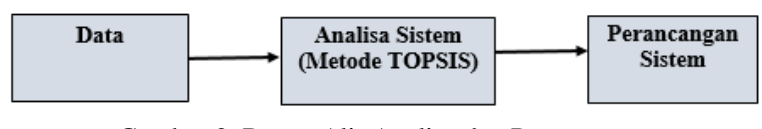

Gambar 2. Bagan Alir Analisa dan Perancangan

Dalam tahap pengumpulan data untuk proses TOPSIS Data yang digunakan pada penelitian ini adalah data dilakukan beberapa cara yaitu, Melakukan pengambilan guru sekolah dasar di kecamatan batang kapas yang data penilaian guru sekolah dasar di kordik wilayah didapat dari korwildikcam batang kapas. Peneliti kecamatan batang kapas melalui persetujuan Kepala menyerahkan surat penelitian yang didapat dari pihak Dinas Pendidikan dan Kebudayan Kabupaten Pesisir kampus kepada bagian pengolahan data di dinas Selatan.

2.5 Melakukan Analisa data dengan Metode Technique For Others Reference by Similarity to Ideal Solution (TOPSIS) Setelah pengumpulan data selesai maka tahapan keberatan memberikan data yang dibutuhkan oleh selanjutnya yaitu melakukan analisis data dengan peneliti. Adapun dalam melakukan proses menerapkan metode TOPSIS.

\subsection{Melakukan perancangan system}

pengumpulan data dilakukan dengan wawancara langsung ke korwildikcam dan pengawas sekolah kemudian mengambil data-data yang diperlukan, data

Pada tahap ini akan dilakukan perancangan terhadap permasalahan yang ada berdasarkan data-data yang telah dikumpulkan dengan tahapan-tahapan yang ada dalam metode TOPSIS.

$2.7 \quad$ Melakukan Implementasi system dan
pengujian

Pada tahap ini dilakukan implementasi dan pengujian terhadap data yang telah diolah dengan bahasa pemrograman PHP. Hal ini bertujuan agar aplikasi yang dirancang dapat bermanfaat bagi penggunanya, sehingga penerapan metode TOPSIS dapat diuji dengan melakukan pencocokan antara hasil perhitungan manual metode TOPSIS dengan hasil perhitungan metode TOPSIS menggunakan aplikasi perangkingan berbasis web.

\subsection{Hasil dan Pembahasan}

Pada tahap ini akan diuraikan hasil dari pengolahan dan $y_{j}^{+}$ pengujian data yang telah dilakukan dengan $D_{i}^{-}$ menggunakan metode TOPSIS. Hasil dari evaluasi $R C$ tersebut akan dijadikan tolak ukur bagi dinas setelah itu pihak dinas pendidikan memberikan rekomendasi kepada korwildikcam batang kapas untuk memberikan data-data yang dibutuhkan oleh peneliti, sehingga pihak korwildikcam bersedia dan tidak yang sudah terkumpul kemudian disusun dalam bentuk tabel di Microsoft excel agar mudah dimengerti dan dapat untuk dipahami dalam tahapan pemprosesan data dan menganalisa data. Adapun data yang digunakan dalam tahapan pemprosesan dan menganalisa data yaitu data penilaian guru sekolah dasar kecamatan batang kapas.

\subsection{Analisa Sistem}

Berdasarkan algoritma proses TOPSIS diatas maka digambarkan melalui psedeucode pada Algoritma 1.

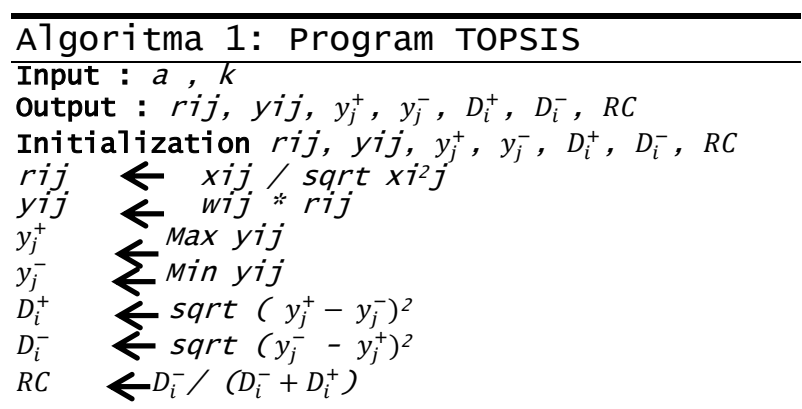


Psedeocode diatas nantinya akan diterapkan kedalam Dimana rij, merupakan alternatif (elemen dari matriks bentuk sistem yang akan dibangun menggunakan ternormalisasi), x_ij merupakan elemen dari matriks bahasa pemrograman PHP menggunakan framework keputusan $\mathrm{x}$.

codeigniter dengan bantuan database MySQL sebagai tempat penyimpanan data.

Pada kriteria 1:

\subsection{Data Alternatif}

Tahapan ini merupakan suatu proses penentuan macam - macam alternatif yang tujuannya untuk memudahkan dalam proses sistem pendukung keputusan dan harus ada alternatif tersebut. Hasil dari penentuan alternatif dapat dilihat pada Tabel 1.

Tabel 1. Alternatif

\begin{tabular}{lll}
\hline No & Nama Guru & Golongan \\
\hline 1 & SW & IV/A \\
2 & ELDS & IV/A \\
3 & NRHD & III/C \\
4 & NF & IV/A \\
5 & NY & III/C \\
6 & IS & III/C \\
\hline
\end{tabular}

$$
\begin{aligned}
& \mathrm{R} 11=\frac{88}{\sqrt{88^{2}+80^{2}+86^{2}+87^{2}+85^{2}+84^{2}}}=0.4225 \\
& \mathrm{R} 12=\frac{80}{\sqrt{88^{2}+80^{2}+86^{2}+87^{2}+85^{2}+84^{2}}}=0.3841 \\
& \mathrm{R} 13=\frac{86}{\sqrt{88^{2}+80^{2}+86^{2}+87^{2}+85^{2}+84^{2}}}=0.4129 \\
& \mathrm{R} 14=\frac{87}{\sqrt{88^{2}+80^{2}+86^{2}+87^{2}+85^{2}+84^{2}}}=0.4177 \\
& \mathrm{R} 15=\frac{85}{\sqrt{88^{2}+80^{2}+86^{2}+87^{2}+85^{2}+84^{2}}}=0.4081 \\
& \mathrm{R} 16=\frac{84}{\sqrt{88^{2}+80^{2}+86^{2}+87^{2}+85^{2}+84^{2}}}=0.4033
\end{aligned}
$$

\subsection{Kriteria dan Kepentingan Bobot}

Tahapan ini merupakan suatu proses penentuan kriteria Pada kriteria 2:

dan nilai bobot dari masing-masing kriteria yang tujuannya untuk memudahkan dalam proses perhitungan pada system pendukung keputusan. Hasil dari penentuan bobot nilai kriteria dapat dilihat pada Tabel 2.

$$
\begin{aligned}
& \mathrm{R} 21=\frac{79}{\sqrt{79^{2}+78^{2}+80^{2}+86^{2}+89^{2}+90^{2}}}=0.3848 \\
& \mathrm{R} 22=\frac{78}{\sqrt{79^{2}+78^{2}+80^{2}+86^{2}+89^{2}+90^{2}}}=0.3800 \\
& \mathrm{R} 23=\frac{80}{79^{2}+78^{2}+80^{2}+86^{2}+89^{2}+90^{2}}=0.3897 \\
& \mathrm{R} 24=\frac{86}{79^{2}+78^{2}+80^{2}+86^{2}+89^{2}+90^{2}}=0.4189 \\
& \mathrm{R} 25=\frac{89}{\sqrt{79^{2}+78^{2}+80^{2}+86^{2}+89^{2}+90^{2}}}=0.4335 \\
& \mathrm{R} 26=\frac{90}{\sqrt{79^{2}+78^{2}+80^{2}+86^{2}+89^{2}+90^{2}}}=0.4384
\end{aligned}
$$

Tabel 2. Kriteria dan kepentingan bobot

\begin{tabular}{llc}
\hline $\begin{array}{l}\text { Simbol } \\
\text { Kriteria }\end{array}$ & Kriteria & $\begin{array}{l}\text { Bobot } \\
\text { Nilai }\end{array}$ \\
\hline C1 & Kompetensi Kepribadian & $20 \%$ \\
C2 & Kompetensi Manajerial & $20 \%$ \\
C3 & Kompetensi Kewirausahaan & $20 \%$ \\
C4 & Kompetensi Supervisi & $20 \%$ \\
C5 & Kompetensi Sosial & $20 \%$ \\
\hline
\end{tabular}

3.6 Data Perbandingan Nilai

Tahapan selanjutnya yang dilakukan adalah membuat tabel perbandingan nilai yang akan dilakukan dalam menghitung perkalian sistem pendukung keputusan. Hasil perbandingan nilai dapat dilihat pada Tabel 3.

Tabel 3. Perbandingan Nilai

\begin{tabular}{lllllll}
\hline No & Nama Guru & C1 & C2 & C3 & C4 & C5 \\
\hline 1 & SW & 88 & 79 & 75 & 67 & 83 \\
2 & ELDS & 80 & 78 & 80 & 78 & 84 \\
3 & NRHD & 86 & 80 & 77 & 80 & 88 \\
4 & NF & 87 & 86 & 89 & 79 & 82 \\
5 & NY & 85 & 89 & 85 & 80 & 90 \\
6 & IS & 84 & 90 & 79 & 86 & 83 \\
\hline
\end{tabular}

3.7. Membuat matriks keputusan ternormalisasi

Tahapan ini merupakan tahapan yang digunakan dalam membuat matriks keputusan ternormalisasi. Dimana rumus yang digunakan dalam menghitung matriks yang disajikan pada Rumus (1)

$$
r i j=\frac{x_{i j}}{\sqrt{\sum_{i=1}^{m} x_{i j}^{2}}}
$$

Pada kriteria 3:

$\mathrm{R} 31=\frac{75}{\sqrt{75^{2}+80^{2}+77^{2}+89^{2}+85^{2}+79^{2}}}=0.3781$

$\mathrm{R} 32=\frac{80}{\sqrt{75^{2}+80^{2}+77^{2}+89^{2}+85^{2}+79^{2}}}=0.4033$

$\mathrm{R} 33=\frac{77}{\sqrt{75^{2}+80^{2}+77^{2}+89^{2}+85^{2}+79^{2}}}=0.3882$

$\mathrm{R} 34=\frac{89}{\sqrt{75^{2}+80^{2}+77^{2}+89^{2}+85^{2}+79^{2}}}=0.4487$

$\mathrm{R} 35=\frac{85}{\sqrt{75^{2}+80^{2}+77^{2}+89^{2}+85^{2}+79^{2}}}=0.4285$

$\mathrm{R} 36=\frac{79}{\sqrt{75^{2}+80^{2}+77^{2}+89^{2}+85^{2}+79^{2}}}=0.3983$

Pada kriteria 4:

$\mathrm{R} 41=\frac{67}{\sqrt{67^{2}+78^{2}+80^{2}+79^{2}+80^{2}+86^{2}}}=0.3483$ 


$$
\begin{aligned}
& \mathrm{R} 42=\frac{78}{67^{2}+78^{2}+80^{2}+79^{2}+80^{2}+86^{2}}=0.4054 \\
& \mathrm{R} 43=\frac{80}{\sqrt{67^{2}+78^{2}+80^{2}+79^{2}+80^{2}+86^{2}}}=0.4158 \\
& \mathrm{R} 44=\frac{79}{\sqrt{67^{2}+78^{2}+80^{2}+79^{2}+80^{2}+86^{2}}}=0.4106 \\
& \mathrm{R} 45=\frac{80}{\sqrt{67^{2}+78^{2}+80^{2}+79^{2}+80^{2}+86^{2}}}=0.4158 \\
& \mathrm{R} 46=\frac{86}{\sqrt{67^{2}+78^{2}+80^{2}+79^{2}+80^{2}+86^{2}}}=0.4470
\end{aligned}
$$

Pada kriteria 5:

$$
\begin{aligned}
& \mathrm{R} 51=\frac{83}{\sqrt{83^{2}+84^{2}+88^{2}+82^{2}+90^{2}+83^{2}}}=0.3984 \\
& \mathrm{R} 52=\frac{84}{\sqrt{83^{2}+84^{2}+88^{2}+82^{2}+90^{2}+83^{2}}}=0.4032 \\
& \mathrm{R} 53=\frac{88}{\sqrt{83^{2}+84^{2}+88^{2}+82^{2}+90^{2}+83^{2}}}=0.4224 \\
& \mathrm{R} 54=\frac{82}{\sqrt{83^{2}+84^{2}+88^{2}+82^{2}+90^{2}+83^{2}}}=0.3936 \\
& \mathrm{R} 55=\frac{90}{\sqrt{83^{2}+84^{2}+88^{2}+82^{2}+90^{2}+83^{2}}}=0.4320 \\
& \mathrm{R} 56=\frac{83}{\sqrt{83^{2}+84^{2}+88^{2}+82^{2}+90^{2}+83^{2}}}=0.3984
\end{aligned}
$$

Hasil dari matriks ternormalisasi dapat dilihat pada Tabel 4.

Tabel 4 Matriks Ternormalisasi

\begin{tabular}{lllllll}
\hline No & Alt & C1 & C2 & C3 & C4 & C5 \\
\hline 1 & SW & 0.4225 & 0.3848 & 0.3781 & 0.3483 & 0.3984 \\
2 & ELDS & 0.3841 & 0.3800 & 0.4033 & 0.4054 & 0.4032 \\
3 & NRHD & 0.4129 & 0.3897 & 0.3882 & 0.4158 & 0.4224 \\
4 & NF & 0.4177 & 0.4189 & 0.4487 & 0.4106 & 0.3936 \\
5 & NY & 0.4081 & 0.4335 & 0.4285 & 0.4158 & 0.4320 \\
6 & IS & 0.4033 & 0.4384 & 0.3983 & 0.4470 & 0.3984 \\
\hline
\end{tabular}

3.8. Membuat matriks keputusan ternormalisasi terbobot

Tahapan ini merupakan tahapan yang digunakan dalam $\mathrm{Y} 46=0.4470 \times 0.2=0.0894$ membuat matriks keputusan ternormalisasi terbobot. dimana rumus yang digunakan dalam menghitung Y51 $=0.3984 \times 0.2=0.0797$ matriks yang disajikan pada Rumus (2).

$$
y i j=w_{i j} r_{i j}
$$

Dimana yij, merupakan elemen dari matriks $\mathrm{Y} 53=0.4224 \times 0.2=0.0845$ normalisasi terbobot, wij merupakan bobot kriteria ke j, dan rij merupakan elemen dari matriks keputusan yang ternormalisasi

Maka hasil yang didapatkan adalah :

$$
\begin{aligned}
& \mathrm{Y} 11=0.4425 \times 0.2=0.0845 \\
& \mathrm{Y} 12=0.3841 \times 0.2=0.0768
\end{aligned}
$$

$$
\begin{aligned}
& \mathrm{Y} 13=0.4129 \times 0.2=0.0826 \\
& \mathrm{Y} 14=0.4177 \times 0.2=0.0835 \\
& \mathrm{Y} 15=0.4081 \times 0.2=0.0816 \\
& \mathrm{Y} 16=0.4033 \times 0.2=0.0807 \\
& \mathrm{Y} 21=0.3848 \times 0.2=0.0770 \\
& \text { Y22 }=0.3800 \times 0.2=0.0760 \\
& \mathrm{Y} 23=0.3897 \times 0.2=0.0779 \\
& \mathrm{Y} 24=0.4189 \times 0.2=0.0838 \\
& \mathrm{Y} 25=0.4335 \times 0.2=0.0867 \\
& \mathrm{Y} 26=0.4384 \times 0.2=0.0877 \\
& \mathrm{Y} 31=0.3781 \times 0.2=0.0756 \\
& \mathrm{Y} 32=0.4033 \times 0.2=0.0807 \\
& \mathrm{Y} 33=0.3882 \times 0.2=0.0776 \\
& \mathrm{Y} 34=0.4487 \times 0.2=0.0897 \\
& \mathrm{Y} 35=0.4285 \times 0.2=0.0857 \\
& \mathrm{Y} 36=0.3983 \times 0.2=0.0797 \\
& \mathrm{Y} 41=0.3483 \times 0.2=0.0697 \\
& \mathrm{Y} 42=0.4054 \times 0.2=0.0811 \\
& \mathrm{Y} 43=0.4158 \times 0.2=0.0832 \\
& \mathrm{Y} 44=0.4106 \times 0.2=0.0821
\end{aligned}
$$

$\mathrm{Y} 45=0.4158 \times 0.2=0.0832$ 
Tabel 5. Matriks ternormalisasi terbobot

\begin{tabular}{lllllll}
\hline No & Alt & C1 & C2 & C3 & C4 & C5 \\
\hline 1 & SW & 0.0845 & 0.0770 & 0.0756 & 0.0697 & 0.0797 \\
2 & ELDS & 0.0768 & 0.0760 & 0.0807 & 0.0811 & 0.0806 \\
3 & NRHD & 0.0826 & 0.0779 & 0.0776 & 0.0832 & 0.0845 \\
4 & NF & 0.0835 & 0.0838 & 0.0897 & 0.0821 & 0.0787 \\
5 & NY & 0.0816 & 0.0867 & 0.0857 & 0.0832 & 0.0864 \\
6 & IS & 0.0807 & 0.0877 & 0.0797 & 0.0894 & 0.0797 \\
\hline
\end{tabular}

3.9. Menentukan nilai solusi ideal positif dan negative

Tahapan ini merupakan tahapan yang digunakan dalam menentukan nilai solusi ideal positif dan negatif. dimana rumus yang digunakan dalam menghitung ini adalah :

Untuk menghitung nilai tertinggi menggunakan Rumus (3) dan (4).

$y_{j}^{+}=\operatorname{Max} y_{i j}$

Untuk menghitung nilai terendah :

$y_{j}^{-}=\operatorname{Min} y_{i j}$

Dimana yi+, merupakan preferensi nilai solusi ideal positif, yi- merupakan preferensi nilai solusi ideal negative, Max yij merupakan nilai maksimal pada negative, $D_{i}^{+}$merupakan jarak alternatif ke 1 dari matriks ternormalisasi terbobot, dan Min yij merupakan solusi ideal positif. Hasil dari menentukan nilai nilai minimal pada matriks ternormalisasi terbobot. preferensi untuk setiap alternatif dapat dilihat pada Hasil dari menentukan nilai solusi ideal positif dan Tabel 8. negatif dapat dilihat pada Tabel 6.

Tabel 6. Nilai solusi ideal positif dan negative

\begin{tabular}{lllllll}
\hline No & Alt & C1 & C2 & C3 & C4 & C5 \\
\hline 1 & Yij+ & 0.0845 & 0.0877 & 0.0897 & 0.0894 & 0.0864 \\
2 & Yij- & 0.0768 & 0.0760 & 0.0756 & 0.0697 & 0.0787 \\
\hline
\end{tabular}

\subsection{Menentukan jarak solusi ideal positif dan 3.12.} negative

Tabel 8. Nilai preferensi untuk setiap alternatif

\begin{tabular}{clc}
\hline No & Alternatif & RC \\
\hline 1 & SW & 0.2218 \\
2 & ELDS & 0.3933 \\
3 & NRHD & 0.4859 \\
4 & NF & 0.6548 \\
5 & NY & 0.7321 \\
6 & IS & 0.6503 \\
\hline
\end{tabular}

Menentukan perangkingan

Tahapan ini merupakan tahapan yang digunakan dalam Tahapan ini merupakan tahapan yang digunakan dalam menentukan perangkingan dalam melakukan penilaian menentukan jarak solusi ideal positif dan negative. sistem pendukung keputusan dengan metode TOPSIS. Dimana rumus yang digunakan dalam menghitung ini Hasil dari menentukan perangkingan dapat dilihat pada adalah :

Untuk Solusi Ideal Positif menggunakan Rumus (5) dan (6).

$\left.D_{i}^{+}=\sqrt{\sum_{j=1}^{n}\left(y_{i}^{+}\right.}-y_{i j}\right)^{2}$

Untuk Solusi Ideal Negatif :

$\left.D_{i}^{-}=\sqrt{\sum_{j=1}^{n}\left(y_{i}^{-}\right.}-y_{i j}\right)^{2}$

Dimana Di+ merupakan, jarak alternatif ke 1 dari solusi ideal positif, Di- merupakan jarak alternatif ke 1 dari solusi ideal negative, yi+ merupakan preferensi nilai solusi ideal positif, yi- merupakan preferensi nilai

solusi ideal negative dan yij merupakan nilai minimal Tabel 7. Jarak solusi ideal positif dan negative

\begin{tabular}{clcc}
\hline No & Alternatif & Di+ & Di- \\
\hline 1 & SW & 0.0274 & 0.0078 \\
2 & ELDS & 0.0195 & 0.0126 \\
3 & NRHD & 0.0170 & 0.0160 \\
4 & NF & 0.0113 & 0.0215 \\
5 & NY & 0.0080 & 0.0219 \\
6 & IS & 0.0127 & 0.0236 \\
\hline
\end{tabular}
alternatif

Tahapan ini merupakan tahapan yang digunakan dalam Dimana rumus adalah :

$$
R C=\frac{D_{i}^{-}}{D_{i}^{-}+D_{i}^{+}}
$$

Dimana $D_{i}^{-}$merupakan kedekatan relative dari alternatif ke 1 terhadap solusi ideal positif. $D_{i}^{-}$ Merupakan jarak alternatif ke 1 dari solusi ideal

\section{in}

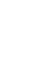


kewirausahaan, supervisi dan sosial. Hasil nilai yang didapatkan bahwa nilai tertinggi terdapat pada alternatif ke 5 dengan nilai 0.7321 dan nilai terendah terdapat pada alternatif ke 1 dengan nilai 0.2218 . Penelitian ini dapat membantu pihak dinas pendidikan dan kebudayaan khususnya korwildikcam batang kapas dalam melakukan rekomendasi penentuan calon kepala sekolah.

\section{Daftar Rujukan}

[1] Daulay, S. (2020). Lecturer Performance Decision Support System Using The TOPSIS Method Based on Web. Journal of Applied Engineering and Technological Science (JAETS), 2(1), 42-49. https://doi.org/10.37385/jaets.v2i1.181

[2] Adela, H., Jasmi, K. A., Basiron, B., Huda, M., \& Maseleno, A. (2018). Selection of dancer member using simple additive weighting. International Journal of Engineering \& Technology, 7(3), 1096-1107. https://doi.org/10.14419/ijet.v7i3.11983

[3] Konstantinos, I., Georgios, T., \& Garyfalos, A. (2019). A decision support system methodology for selecting wind farm installation locations using AHP and TOPSIS: Case study in Eastern Macedonia and Thrace region, Greece. Energy Policy, 132, 232-246. https://doi.org/10.1016/j.enpol.2019.05.020

[4] Seyedmohammadi, J., Sarmadian, F., Jafarzadeh, A. A., Ghorbani, M. A., \& Shahbazi, F. (2018). Application of SAW, TOPSIS and fuzzy TOPSIS models in cultivation priority planning for maize, rapeseed and soybean crops. Geoderma, 310, 178-190. https://doi.org/10.1016/j.geoderma.2017.09.012

[5] Susliansyah, S., Rahadjeng, I. R., \& Sumarno, H. (2019). penerapan metode topsis dalam penilaian kinerja guru tetap sd negeri kebalen 07. Jurnal Pilar Nusa Mandiri, 15(1), 7-14. https://doi.org/10.33480/pilar.v15i1.

[6] Perwira, Y. (2021). Sistem Pendukung Keputusan Pemilihan Guru Berprestasi Di Smk Negeri 1 Pantai Labu Dengan Menggunakan Metode Technique For Order Of Preference By Similarity To Ideal Solution (Topsis). Jurnal Ilmu Komputer dan Sistem Informasi (JIKOMSI), 3(3), 229-250. https://doi.org/10.32672/jnkti.v3i3.2418

[7] Lei, F., Wei, G., Gao, H., Wu, J., \& Wei, C. (2020). TOPSIS method for developing supplier selection with probabilistic linguistic information. International Journal of Fuzzy Systems, 1-11. https://doi.org/10.1007/s40815-019-00797-6

[8] Surya, C. (2018). Penilaian Kinerja Dosen Menggunakan Metode TOPSIS (Studi Kasus: Amik Mitra Gama). JURNAL
RESTI (Rekayasa Sistem dan Teknologi Informasi), 2(1), 322329. https://doi.org/10.29207/resti.v2i1.119

[9] Kwok, P. K., \& Lau, H. Y. (2019). Hotel selection using a modified TOPSIS-based decision support algorithm. Decision Support Systems, 120, 95-105. https://doi.org/10.1016/j.dss.2019.02.004

[10] Prihatin, T. (2019). Perbandingan Metode TOPSIS Dan SAW Dalam Penentuan Guru Berprestasi. Jurnal Teknik Komputer, 5(1), 29-34. https://doi.org/10.31294/jtk.v5i1.4706

[11] Kong, X., Yan, L., Wang, D., Yu, M., \& Liu, X. (2020, November). Evaluation of Education Resources Allocation in Beijing Based on Entropy-TOPSIS Method. In Journal of Physics: Conference Series (Vol. 1670, No. 1, p. 012042). IOP Publishing. https://doi.org/10.1088/1742-6596/1670/1/012042

[12] Topadang, A., \& Nurcahyono, D. (2019). analisis metode TOPSIS dalam sistem pendukung keputusan penentuan guru berprestasi pada sekolah menengah pertama negeri 8 samarinda. Just TI (Jurnal Sains Terapan Teknologi Informasi), 11(2), 711. https://doi.org/10.46964/justti.v11i2.144

[13] Alawiyah, T., Supriatin, T., Sutisna, H., Hikmah, A. B., \& Simpony, B. K. (2020). Implementasi Metode TOPSIS Pada Sistem Pendukung Keputusan Penerima KKS Pada Desa Tawang. Indonesian Journal on Software Engineering (IJSE), 6(2), 152-162. https://doi.org/10.31294/ijse.v6i2.8960

[14] Fadli, S., \& Zaen, M. T. A. (2018). Penggunaan Metode Techique for Order Preference by Similarity to Ideal Solution (TOPSIS) untuk Evaluasi Kinerja Dosen oleh Mahasiswa (Studi Kasus: STMIK Lombok). JISA (Jurnal Informatika dan Sains), 1(1), 7-13. https://doi.org/10.31326/jisa.v1i1.295

[15] Maspiyanti, F. (2020). Sistem Pendukung Keputusan Pemilihan Guru Terbaik Menggunakan Metode Simple Additive Weighting Dan Topsis. Jurnal Ilmiah Informatika (JIF), 8(2), 128-135. https://doi.org/10.47047/ct.v7i2.100

[16] Dutta, B., Dao, S. D., Martínez, L., \& Goh, M. (2021). An evolutionary strategic weight manipulation approach for multiattribute decision making: TOPSIS method. International Journal of Approximate Reasoning, 129, 64-83. https://doi.org/10.1016/j.ijar.2020.11.004

[17] Kurnia, Y. (2018). Penilaian Kinerja Guru Menggunakan Metode Topsis. Journal Scientific and Applied Informatics, 1(3), 70-75. https://doi.org/10.36085/jsai.v1i3.63 